\title{
Mental illness in the medical profession: Nigeria in the world*
}

\author{
A. O. Ogunlesi, Senior Consultant Psychiatrist; and E. O. AKande (Psychologist), \\ Aro Neuropsychiatric Hospital \& WHO Collaborating Centre for Research \& \\ Training in Mental Health, P.M.B. 2002, Abeokuta, Nigeria
}

It is widely acknowledged that the medical profession can be highly stressful. In addition, practitioners in many developing countries face the peculiar problems of poor remuneration, lack of necessary clinical facilities and a heavy clinical case load (due to the lack of qualified manpower). Such a scenario can easily aggravate those medical practitioners with pre-existing deeply rooted emotional conflicts as well as personality vulnerabilities and can result in mental decompensation.

There is a dearth of information on mental illness in the medical profession in Nigeria and this motivated the present inquiry, conducted at the Nigerian National Neuropsychiatric Hospital, Abeokuta. This premier psychiatric hospital, which was established in 1954, has 526 beds and has been managed since inception by three consultant psychiatrists on average. It has no defined catchment area. This review discusses the demography and clinical characteristics of the mentally ill medical and dental practitioners as well as medical students seen at the hospital between 1972-1990.

\section{Findings}

The study group included $19(73.1 \%)$ doctors, 2 $(7.7 \%)$ dentists and $5(19.2 \%)$ medical students. Their ages ranged between 20-62 years and mean age/standard deviation was 31.6 years \pm 10.54 . There were $22(84.6 \%)$ Nigerians and $4(15.4 \%)$ foreigners.

With regard to employment status at their last consultation, $17(65.4 \%)$ were in employment, 2 (7.7\%) were not employed for at least a year preceding last consultation (both were chronic schizophrenics), $2(7.7 \%$ ) were retired (one voluntarily and the other, an alcoholic, was compulsorily retired on health grounds). The rest were medical students.

They experienced their first illness as medical students in 11 cases, while in 12 cases the first illness occurred after they qualified as a doctor. The timing of the first illness was unknown in three cases.

* Based on a paper read at the Annual General Meeting of the Association of Psychiatrists in Nigeria held in Jos, September 1991.
There was a positive history of drug abuse at some time in the past or currently in eight $(30.8 \%)$ cases and this was negative in 17 cases. Information was unavailable on one case. Cannabis, cocaine, and amphetamine were abused by five out of eight.

Fifteen $(57.7 \%)$ were diagnosed as suffering from schizophrenia and one was neurotic. The remainder included those suffering from paranoid psychosis (1), depressive illness (2), drug induced psychosis (2), drug dependence (3), psychosis not otherwise specified (1), and epilepsy (1).

The frequency of the management problems presented during therapy were as follows: defaulting (57.7\%), poor drug compliance $(42.3 \%)$, absconding $(11.5 \%)$, rationalisation of symptoms $(19.2 \%)$ and discharge against medical advice (3.8\%).

Out of the five medical students, two did not complete their medical training and had to change to less rigorous courses, one was still on the course and there was no information on the progress of two.

When contact with the hospital in the last one year was assessed, $10(38.5 \%)$ were still in contact while 16 $(61.5 \%)$ were no longer in contact.

\section{Comment}

One out of every five patients in this study was a medical student and almost five out of every ten patients studied started having psychiatric illness as medical students. These findings underscore the importance of having a facility for mental health assessment in university health centres as well as the need to ensure that those manning such health centres are adequately equipped to handle mental health crises in students. It is suggested that psychiatrists in developing countries should endeavour to provide consultation outlets in nearby university health centres in spite of their usually intensive hospital commitment.

Many of the studies on psychiatric morbidity in medical practitioners in the technologically advanced countries highlight the fact that substance abuse/dependence is prevalent in the medical profession and that it is an occupational hazard (Duffy \& Litin, 1964; a 'Brook et al, 1967; Murray, 1974). The 
available information in Nigeria as gleaned from the present report suggests that functional pyschoses may be predominant while neurotic illness as well as suicide are apparently rare.

The rarity of suicide in the region in which this hospital is located has previously been highlighted (Asuni, 1962). It is, however, of interest to remark that the only incident of suicide in the present study occurred in a foreign general duty doctor working in the hospital under study.

The finding in this study suggests that mental illness in the subjects did not significantly affect their employment status (as only one out of every ten had either not been employed for at least a year before consultation or had been retired as a consequence of illness). It will be interesting to establish how optimally those who are employed are functioning.

In the experience of the first author, there are often formidable difficulties that are posed by mentally il doctors in the course of management. In the present study, almost six out of every ten subjects defaulted from out-patient surveillance and about four out of every ten were noted to be complying poorly with out-patient medication. Medical practitioners in developing countries are more likely to be viewed on a pedestal by the population. The emergence of mental illness in them is therefore accompanied by feelings of frustration, anger, loss of confidence, shame, intense denial and rationalisation. The 'defensive' responses eventually result in management problems that may task the expertise of an experienced psychiatrist.

While no attempt has been made in this study to discern the motives underlying defaulting in the subjects studied, it is possible that as a result of the often busy schedule of doctors, coupled with the lack of psychiatric expertise and clinics, it may not be convenient to keep appointments in a far away psychiatric clinic (only about a third of the subjects studied/lived/worked in the state in which this hospital is located, while the remainder had to travel from other states). It is suggested that in following up medical professionals, attempts should be made to encourage them to receive follow-up care with the psychiatrist nearest to them.

There is still a wide lacuna in our understanding of psychiatric illnesses in the medical profession in Nigeria and the present study may not be entirely free of distortion by certain factors. It is possible that some doctors may have been seen privately in the hospital during the study period without case-notes being opened for them as a way of protecting their identity. Psychiatrists should endeavour to discourage this consultation approach as it mitigates against proper record keeping and research.

Finally, it is disquieting that the medical profession in Nigeria has not evolved any workable policy for dealing with mentally ill doctors to ensure that the public who come under their care are adequately protected. Psychiatrists in Nigeria ought to give a lead in this direction.

\section{References}

a 'Brook, M. F., Hailstone, J. D. \& McLauchlan, I. E. J. (1967) Psychiatric illness in the medical profession. British Journal of Psychiatry, 113, 1013-1023.

AsUnI, T. (1962) Suicide in Western Nigeria. British Medical Journal, 2, 1091-1097.

DufFY, J. C. \& LiTIN, E. M. (1964) Psychiatric morbidity of physicians. Journal of American Medical Association, 189, 989-992.

MURRAY, M. (1974) Psychiatric illness in doctors. Lancet, 1, 1211-1213. 